\title{
AN OBSERVATION OF BIRD MORTALITY ON HIGHWAYS
}

\author{
by Keith D. Baker, Hanover, New Hampshire
}

During February 1963 my wife and I had occasion to travel by car from the south shore of the Gulf of S.t. Lawrence to New Hampshire. The state of Maine had been hit with one of the largest snowfalls in memory and we were treated to some spectacular scenery. Besides the massive snow drifts, we took an interest in the bird life that we saw from time to time.

One of our overnight stops was with a friend, George Sawyer, Jr., of Ashland, Maine. Mr. Sawyer is a forester and naturally a good deal of his time is spent in the outdoors. We discussed in particular the peculiar habit of the small birds which flocked to the middle of the roads, especially in the bare spots where the snow had melted leaving bare patches of road and small shallow puddles of water. The small birds watering, or whatever the attraction, seemed almost oblivious of the passing vehicles. At modern highway speeds, even in the wintertime, the decimation was enormous. On close examination of the bird flocks we found that the predominating species was the Whitewinged Crossbill. The other bird that accompanied the crossbills was the Pine Siskin. Probably because of their slightly smaller size there were few siskin fatalities. It was snowing from time to time during our observation of the slaughter, a condition that obliterated many of the bodies, feathers and traces, yet the road and bordering snowbanks could be said to be covered with dead birds. Snowploughs and blowers moving along the highway also were covering the remains rapidly. Scavenging crows were patrolling the roadways and picking off crippled birds. We tried many ways to force the birds to rise off the road before the arrival of our vehicle - loud shouting and whistling out the car window, honking of the car horn, racing the motor, flashing the headlights or combinations of these. None of these devices was successful.
The area is heavily forested and the major industry in the winter is lumbering. Much of the area is virtually inaccessible except in winter when the ground freezes sufficiently to allow the heavy lumbering vehicles to move about. We saw many trucks with large loads of logs make their deliveries to the mills or stockpiles.

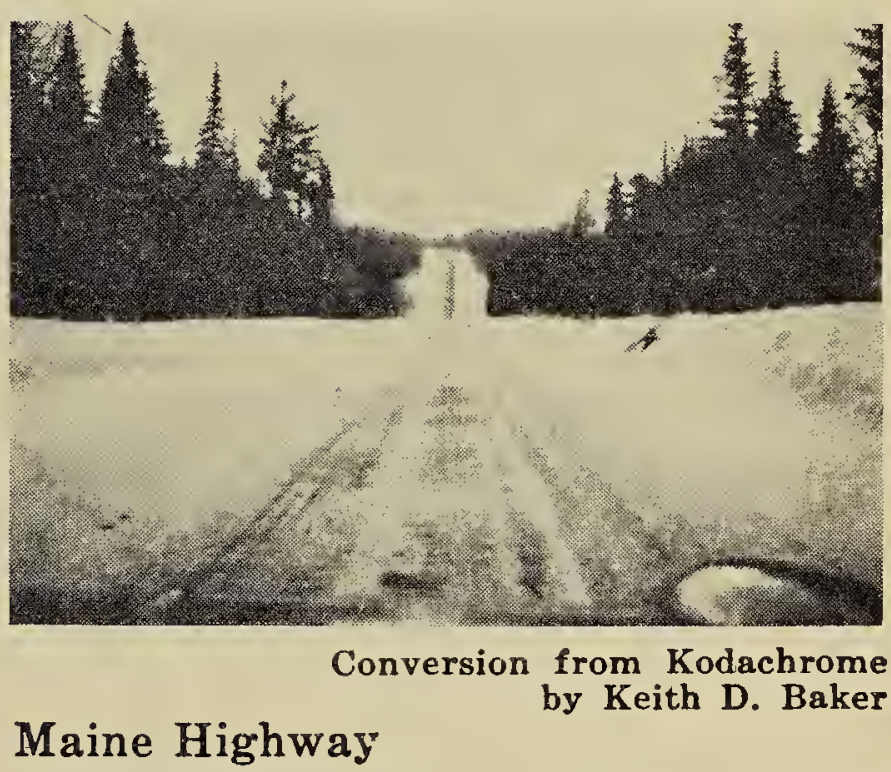

Even at moderate speed the impact on the bird flocks was fantastic. We followed a number of these large trucks, both loaded and empty, as well as ordinary conveyances to see them time and time again bear down on the birds and fling them spinning into the air. We noted that there were few cripples from these onslaughts. The birds died almost immediately when struck or were crushed underfoot. On examination we found that a great many of the dead birds did not even have a ruffled feather on their bodies.

The local inhabitants for the greater part looked upon this bird slaughter as a natural and everyday occurrence. For us this was an entirely new experience; we had never seen this type of bird mortality on such a scale. On query, since we had not had the opportunity to view the two species under any other conditions, we found that the birds were of similar habits. They are reputed to be active in their 
movements in their normal habitat of the forests. They apparently are not shy or particularly timid but would normally fly at the approach of man or machine. Considering the normal reflexes of ibirds of this size and their usually rapid actions it would seem that there must be some reason for their inability to escape collision with the modern day car or truck on the highway. One clue might be their fatal fascination for the muddy, briny water around which they watered. Would not snow suffice for a thirstquencher? Were their usual supplies of water inaccessible or frozen? It might be that the chemicals used to melt snow on the highways have a particular effect on these birdis.

Editor's Note-Mr. Baker's suggestion that the birds were attracted to the road by the salt used on it to melt the snow undoubtedly answers the question of why such large flocks were encountered and killed on the Maine highway. It has been pointed out by ornithologists that "some winter finches seem to crave salt especially, perhaps because of mineral deficiencies in their customary diet" (G. J. Wallace. 1955. An introduction to ornithology. Macmillan Co., New York, p. 319). In this connection Wing might also be quoted (L. W. Wing. 1956. Natural history of birds. Ronald Press Co., N.Y., p. 92) because he mentions some of the species that seem particularly attracted: "Field observations indicate that Doves, Crossbills, Pine Grosbeaks, Purple Finches, Evening Grosbeaks, and other species regularly resort to 'salt licks.' Analysis of several such licks in the West shows that the water-soluble salts present include chlorides, sulphates, hydrocarbonates, and carbonates of sodium. Some magnesium and calcium salts may also be present."

\title{
SOME FEEDING HABITS OF THE RUBY-THROATED HUMMINGBIRD
}

\author{
by Alvin Binnie, Regina
}

Last summer (1964) I had the good fortune to be able to observe closely some feeding habits and preferences of the Ruby-throated Hummingbird. The ability of these helicopters of the bird world to seek out and take advantage of the drilling of the Yellowbellied Sapsucker came as a distinct surprise to me.

I chanced upon this association while seeking additional water supplies for a cattle herd in the Qu'Appelle Valley, north of Regina. It was late July and the morning was very hot. I climbed a ledge protruding from the southern slope to investigate a tiny itrickle of water. Pausing to rest in the welcome shade of a grove of poplars, I noticed a male sapsucker vigorously drilling alternately in a white birch and a white poplar. While thus engaged he was closely pursued by two juveniles, clamoring to be fed. I had barely time to digest the fact that Yellow-bellied Sapsuckers nested in the area (four miles east of No. 6 Highway) when a pair of Ruby- throated Hummingbirds appeared on the scene. They moved from hole to hole gathering sap from both poplar and birch. Interestingly enough, a similar observation from this very area in the Qu'Appelle has since been reported to me. About two miles west of No. $6 \mathrm{Highway,} \mathrm{and} \mathrm{hence} \mathrm{only} \mathrm{five}$ miles from my site, on June 24, 1964, R. W. Nero and G. F. Ledingham watched adult male and female Rubythroats feeding in mid-afternoon at fresh sapsucker holes in an aspen on the forested south slope of the valley.

The opportunity to observe this feeding procedure for the second time came to me on August 5 at Moose Mountain Provincial Park. On this occasion the sapsuckers were drilling only in white birch and only where some thoughtless person had stripped away the outer bark. Several trees were completely ringed with holes and nowhere were the holes more than two inches apart. We actually saw a pair of adult hummers feeding on the 